\title{
Les politiques linguistiques, la France et l'Europe : bibliographie sommaire
}

Jean Rousseau

\section{OpenEdition}

1 Journals

Édition électronique

URL : http://journals.openedition.org/ries/4247

DOI : 10.4000/ries.4247

ISSN : 2261-4265

Éditeur

Centre international d'études pédagogiques

\section{Édition imprimée}

Date de publication : 1 septembre 1994

Pagination : 135-137

ISSN : 1254-4590

\section{Référence électronique}

Jean Rousseau, «Les politiques linguistiques, la France et l'Europe : bibliographie sommaire », Revue internationale d'éducation de Sèvres [En ligne], 03 | 1994, mis en ligne le 17 avril 2015, consulté le 01 ma 2019. URL : http://journals.openedition.org/ries/4247 ; DOI : 10.4000/ries.4247

Ce document a été généré automatiquement le 1 mai 2019.

(c) Tous droits réservés 


\section{Les politiques linguistiques, la France et l'Europe : bibliographie sommaire}

Jean Rousseau

\section{Sociolinguistique}

2 HOLMES J., An Introduction to Sociolinguistics. London \& New York, 1992.

3 WARDHAUGH R., An Introduction to Sociolinguistics. Oxford \& Cambridge, 1992.

\section{Planification linguistique; généralités et études de cas}

4 CALVET L.J., Linguistique et colonialisme. Paris, 1974.

5 CALVET L.J., « Typologie des politiques linguistiques », in GRUENAIS M.P. (éd.), États de langue. Peut-on penser une politique linguistique? Paris, 1986.

6 CALVET L.J., La Guerre des langues et les politiques linguistiques. Paris, 1987.

7 CHRISTIAN D., "Language planning : the view from linguistics", in NEWMEYER F.J. (éd.), Linguistics : the Cambridge Survey. IV. Language : the Socio-cultural Context. Cambridge, 1986.

8 DAS GUPTA J., Language Conflict and National Development : Group Politics and National Policy in India. Berkeley, 1970.

9 FISHMAN J.A., FERGUSON CA., DAS GUPTA J. (éd.), Language problems of developing Nations. New York, 1968.

10 FODOR I. \& HAGEGE C, Language Reform. La Réforme des langues. Sprachreform. 5 vol. Hamburg, 1983-1984. 
GUESPIN L. \& MARCELLESI J.B. (éd.), « Glottopolitique », Langages, n 83, Paris, sept. 1986.

HAUGEN E., Language Conflict and Language Planning: The case of Modern Norwegian. Cambridge MA., 1966.

LAPIERRE J.W., Le pouvoir politique et les langues. Babel et Léviathan. Paris, 1988.

La guerre des langues, Hérodote, $n^{\circ} 42$, Paris, $3^{\mathrm{e}}$ trim. 1986.

LEHMANN W.P. (éd.), Language and Linguistics in the People's Republic of China. Austin, 1975.

MAURAIS J. (éd.), Politique et aménagement linguistiques. Paris \& Québec, 1987.

WARDHAUGH R., Language and Nationhood The Canadian Experience. Vancouver, 1983.

WHITELEY W.H., Swahili : The Rise of a National Language. London, 1969.

\section{Les langues de France}

CERTEAU M. de, JULIA D., REVEL J., Une politique de la langue. La Révolution française et les patois. Paris, 1975.

CITRON S., Le mythe national : l'histoire de France en question. Paris, 1991.

GIORDAN H. \& VERBUNT G., Par les langues de France. 2 vol. , Paris, 1984-1985.

GORDON D.C., The French Language and National Identity (1930-1975). The Hague, 1978.

HAGEGE C, Le Français et les siècles. Paris, 1989.

MARCELLESI J.B. \& le G.R.E.C.O. (éd.), «L'enseignement des langues régionales », Langue française, $\mathrm{n}^{\circ}$ 25, Paris, fév. 1975.

MARTEL P., Les langues de France aujourd'hui, in Universalia 1986. Paris, 1986.

«Minorités nationales en France aujourd'hui », Les Temps modernes, n 324-326, Paris, 1973.

MULLER B., Le Français d'aujourd'hui, Paris, 1985.

« Pluralité des parlers en France », Ethnologie française, n³, Paris, 1973.

PICOCHE J. \& MARCHELLO-NIZIA C., Histoire de la langue française. Paris, 1989.

SANDERS C. (éd.), French today. Language in its social context. Cambridge, 1993.

TABOURET-KELLER A. (éd.), «Regional languages in France aujourd'hui », International Journal of the Sociology of Language, $\mathrm{n}^{\circ} 29$ The Hague, 1981.

VERMES G. \& BOUTET J. (éd.), France, pays multilingue. I. Les langues en France, un enjeu historique et social, II. Pratiques des langues en France. Paris, 1987.

VERMES G. (éd.), Vingt-cinq communautés linguistiques de la France. I. Langues régionales et langues non territorialisées, II. Les langues immigrées. Paris, 1988.

WALTER H., Le Français dans tous les sens. Paris, 1988.

WEBER E., La fin des terroirs: la modernisation de la France rurale. Paris, 1983 (édit, américaine : 1976).

\section{L'Europe et les minorités}

CALVET L.J., L'Europe et ses langues. Paris, 1993. 

répandues: 1983-1989. Dublin \& Wilwerwith: Bureau européen pour les langues moins répandues, [1991].

DECAUX E., «Le droit international et la protection des minorités », in GIORDAN H. \& BISTOLFI R. (1991).

DEMICHEL A., Article « Minorités », in Encyclopaedia Universalis, vol. 15. Paris, 1990.

DE WITTE B., «The Impact of European Community Rules on Linguistic Policies of the Member States", in COULMAS F. (éd.), A Language Policy for the European Community. Prospects and Quandaries. Berlin \& New York, 1991.

FOSTER CR. (éd.), Nations without a State: Ethnic Minorities in Western Europe. New York, 1980.

GELLNER E., Nations et nationalisme, Paris, 1989 (édit, anglaise : 1983).

GIORDAN H. \& BISTOLFI R. (éd.) « Minorités : quelles chances pour l'Europe », L'Événement européen, n 16, Paris, oct. 1991.

GIORDAN H., "Las lenguas minoritarias patrimonio de la humanidad », Idiomas, n 11, Madrid, mai-juin 1992.

HAGEGE C, Le Souffle de la langue : voies et destins des parlers d'Europe. Paris, 1993.

HERAUD G., L'Europe des ethnies. Bruxelles \& Paris, 1993.

JACOBY L., Les activités des Communautés européennes en faveur des langues et cultures moins LABRIE N., La construction linguistique de la communauté européenne. Paris, 1993.

SMITH A.D., The Ethnic revival. Cambridge, 1981.

STRAKA M. (éd.), Handbuch der europäischen Volksgruppen. Wien \& Stuttgart, 1970.

THOMIERES D (éd.), Le citoyen de demain et les langues: la dimension politique de l'apprentissage des langues. Paris: Association des professeurs de langues vivantes de l'enseignement public, 1985.

\section{AUTEUR}

\section{JEAN ROUSSEAU}

Centre international d'études pédagogiques (CIEP). 